\title{
Avaliação de diferentes técnicas de coloração para esfregaços obtidos por punção biópsia aspirativa testicular de bovinos
}

Evaluation of different coloration techniques for smears obtained by aspiration biopsy puncture of bull testis

Yolanda Henrichs Garcia Bandeira Bastos ${ }^{1}$, Cristiano Silva Ferreira ${ }^{2}$, Gustavo Mendes Gomes ${ }^{1}$, Kleber da Cunha Peixoto Júnior ${ }^{2}$, Letícia Patrão de Macedo Gomes ${ }^{1}$, Frederico Ozanam Papa ${ }^{3}$, André Maciel Crespilho ${ }^{1,2}$.

\begin{abstract}
Resumo
Os corantes Panótico Rápido e Giemsa são frequentemente utilizados para a avaliação de células de linhagem espermatogênica, porém nenhuma destas colorações foi desenvolvida especificamente para o processamento tintorial desse tipo celular. Como até presente não existe consenso na literatura sobre qual das técnicas de coloração permite a melhor visualização das células germinativas testiculares, o objetivo deste estudo foi determinar a melhor coloração para esfregaços obtidos por punção biópsia aspirativa testicular (PBA) de bovinos. Foram selecionados 25 machos bovinos adultos, que sofreram PBAs em ambos os testículos ( $\mathrm{n}=50$ punções biópsia aspirativas, perfazendo um total de 100 esfregaços testiculares). O conteúdo de cada PBA foi utilizado para a confecção de no mínimo 2 esfregaços em lâminas foscas de vidro que posteriormente foram corados utilizando dois métodos distintos: Panótico Rápido (G1, n=50 esfregaços) ou Giemsa (G2, n=50). Para avaliação da qualidade dos esfregaços as células da linhagem espermatogênica foram contabilizadas e comparadas entre os dois grupos experimentais. A facilidade e nitidez de visualização proporcionada por cada uma das técnicas foi comparada atribuindo-se uma nota de 1 a 3 (1: ruim; 2: regular; 3: boa). A coloração Panótico Rápido permitiu a identificação de maior quantidade de espermatócitos secundários $(\mathrm{p}=0,0042)$ e células inflamatórias $(\mathrm{p}=0,0318)$, apresentando ainda efeito significativo sobre a qualidade de leitura dos esfregaços $(p=0,0087)$. Embora ambas as colorações permitam a identificação e visualização das estruturas da linhagem espermatogênica, o Panótico Rápido permitiu melhor visualização e avaliação das células testiculares. Palavras-chave: Punção biópsia aspirativa. Citologia testicular. Touros. Panótico Rápido. Giensa.
\end{abstract}

\begin{abstract}
The Diff-Quick and Giemsa dye are frequently used to evaluate the germ cells, but any one was developed for the specific evaluate of this kind of cells, no existing until now, agreement in the literature about which this techniques of dye allows the best preview of the germ cells. This way, the aim of this study was determine the best dye of smears obtained with testicular aspiration biopsy puncture (TABP) of cattle. Was selected 25 males bovines adults who suffer TABP in both testicles ( $\mathrm{n}=50$ puncture aspiration biopsy, making a total of 100 testicular smears). The content of each TBP was used to production of at least 2 smears that later was ruddy using two different methods: Diff-Quick ( $\mathrm{n}=50$ ) or Giemsa $(\mathrm{n}=50)$. For the evaluate the quality of the smears the germ cells was accounted and for the determination of the best coloration techniques the cytological blades was evaluated in differential count obtained at the samples ruddy with Diff-Quick front of ruddy with Giemsa. In addition, the quality in in cellular differentiation was compared between the two groups using a scale 1 to 3 (1=bed, $2=$ regular, $3=$ good quality of coloration). As a result was obtained that Diff-Quick coloration allowed the preview of largest amount of secundary spermatocytes $(p=0,0042)$ and inflammatory cells $(\mathrm{p}=0,0318)$, still presenting significant result about read quality of smears $(\mathrm{p}=0,0087)$. Although both colorations allow the identification and the preview of the germ cells, the Diff-Quick allowed the best preview of this kind of cells. Keywords: Bulls. Diff. Quick. Giemsa. Testicular aspiration biopsy puncture. Testicular cytology.
\end{abstract}

\section{Introdução}

Para obtenção de resultados satisfatórios de fertilidade se faz necessário à criteriosa seleção de reprodutores, sendo essencial não apenas para a determinação do potencial de fertilidade dos touros, como também para a identificação de anormalidades que possam comprometer o desempenho reprodutivo do animal. ${ }^{1}$ Tradicionalmente o exame andrológico é composto pela avaliação clínica reprodutiva e pela análise da qualidade, morfologia e viabilidade espermática, ${ }^{2}$ parâmetros frequentemente utilizados para a seleção de reprodutores.

No âmbito da avaliação do trato reprodutivo, novas técnicas como a ultrassonografia e punção biópsia aspirativa testicular (PBA) vem sendo inseridas como métodos complementares que apresentam grande utilidade para identificação de touros sub férteis. ${ }^{3}$ A PBA ou punção aspirativa por agulha fina (PAAF) figura como método auxiliar para avaliação da saúde testicular, fornecendo material para avaliação citológica da espermatogênese. ${ }^{4} \mathrm{~A}$ avaliação citológica

1. Universidade Severino Sombra, USS, Vassouras-RJ, Brasil.

2. Universidade de Santo Amaro, UNISA, São Paulo-SP, Brasil.

3. Universidade Estadual Paulista Júlio de Mesquita Filho, UNESP, Botucatu-SP, Brasil 
permite a análise morfológica das células testiculares ${ }^{5}$ e tem se mostrado uma ferramenta de grande utilidade para o diagnóstico de lesões na gônada masculina, sendo indicada em casos de aumento de volume dos testículos ou na avaliação de animais azoospérmicos ou oligospérmicos. $^{6}$

$\mathrm{Na}$ citologia testicular é realizado o estudo da morfologia das células de linhagem espermatogênica, estruturas naturalmente translúcidas e de difícil visualização sem um preparo tintorial adequado para avaliação sob microscopia de luz. ${ }^{1}$ Nesse sentido, na rotina dos laboratórios de Patologia Clínica Veterinária os corantes Panótico Rápido e Giemsa geralmente se destacam como os mais utilizados para a avaliação de uma grande variedade de células. ${ }^{7,8}$ Essas colorações são consideradas tipo Romanowsky e apresentam boas propriedades tintoriais para avaliação de características nucleares e diferenciação do núcleo e citoplasma. ${ }^{5}$ Além disso, Panótico e Giensa podem ser consideradas como colorações de escolha na prática veterinária devido ao baixo custo, praticidade e facilidade de execução associada à qualidade de visualização da morfologia celular. ${ }^{9}$ No entanto, como nenhum desses corantes foi desenvolvido para avaliação específica das células testiculares, até o presente não existe um consenso na literatura sobre qual das técnicas de coloração permite a melhor visualização de esfregaços obtidos por PBA.

Embora diferentes trabalhos conduzidos anteriormente tenham demonstrado que ambas as colorações foram efetivas para o processamento de esfregaços produzidos a partir de PBA testicular, até o presente não existem estudos comparando a qualidade tintorial proporcionada por Giensa ou Panótico, questão fundamental para a padronização da técnica, uniformidade de leitura e interpretação dos resultados das punções aspirativas.

Dessa forma, o presente trabalho teve por objetivo determinar a melhor coloração para esfregaços obtidos por punção biópsia aspirativa testicular de bovinos.

\section{Material e Métodos}

O experimento foi realizado na fazenda Pirauí localizada no município de Vassouras/Rio de Janeiro, tendo recebido aprovação do Comitê de Ética no Uso de Animais da Universidade Severino Sombra, parecer CEUA n ${ }^{\circ}$ 005/2014.

Foram selecionados 25 bovinos machos mestiços (Holandês/Gir) com idade entre 24 e 36 meses, que sofreram PBAs em ambos os testículos ( $\mathrm{n}=50$ punções biópsia aspirativas, perfazendo um total de 100 esfregaços testiculares). Para realização das PBAs os animais foram contidos em tronco de contenção próprio para a espécie. Após prévia assepsia com solução de iodopovidona a $1 \%$ os animais foram submetidos à PBA no testículo direito e posteriormente no esquerdo. Para realização das PBAs cada testículo foi individualizado e seguro manualmente. Foram utilizadas seringas estéreis de $20 \mathrm{~mL}$ acopladas a agulhas $25 \times 7$ que foram introduzidas perpendicularmente ao parênquima testicular em direção à região crânio-lateral de cada testículo. Após a completa inserção das agulhas o êmbolo das seringas era puxado integralmente para trás criando o vácuo necessário para a aspiração das células da linhagem espermatogênica.

Durante as punções a agulha foi movimentada para fora e para dentro dos testículos duas a três vezes por aproximadamente quatro segundos, protocolo que segundo Leme e Papa, ${ }^{6}$ é eficiente para promover desalojamento celular, facilitando a sucção do material para dentro do canhão da agulha. O conteúdo de cada aspirado testicular foi utilizado para a confecção de no mínimo 2 esfregaços em lâminas foscas de vidro, posteriormente coradas utilizando dois métodos distintos: Panótico Rápido (Grupo1, n=50 esfregaços) ou Giemsa (Grupo 2, n=50).

Para coloração com Giemsa foi utilizado o protocolo proposto por Olicheski. ${ }^{10}$ Inicialmente cada esfregaço foi pré fixado em álcool metílico por 3 minutos. Após a retirada do excesso de álcool as lâminas de vidro foram posicionadas em raques horizontais, recobertas com o corante Giemsa por 10 minutos. Em seguida as lâminas foram lavadas em água corrente e secas ao ar para a visualização em microscopia de luz.

Para coloração com Panótico Rápido foi utilizado kit hematológico comercial (Laborclin ${ }^{\circledR}$ produtos para laboratórios Ltda., Pinhais, PR, Brasil). Seguindo as recomendações do fabricante, cada lâmina de vidro foi inicialmente imersa em uma solução de triarilmetano a $0,1 \%$ por 10 segundos, exercendo movimentação constante. Após essa fixação inicial as lâminas foram imersas em solução de xantenos a $0,1 \%$ por 10 segundos e posteriormente em solução de tiazinas a $0,1 \%$ por mais 10 segundos. Após a última imersão as lâminas foram lavadas em água corrente e secas ao ar previamente à avaliação microscópica.

Para avaliação da qualidade dos esfregaços as células da linhagem espermatogênica foram classificadas de acordo com Papa e Leme ${ }^{11}$ : espermatogônias, espermatócitos primários, secundários, espermátides iniciais, espermátides maduras (células na fase de alongamento durante a espermiôgenese), espermatozoides e células de Sertoli, sendo ainda contabilizadas as células inflamatórias. Para cada esfregaço foram contadas 200 células.

Para determinação da melhor técnica de coloração as lâminas citológicas foram avaliadas em duplicata em microscopia de luz sob aumento de 1000x, comparandose a contagem diferencial obtida nas amostras coradas com Panótico frente às coradas em Giemsa. Além disso, a qualidade na diferenciação celular foi comparada entre 
os dois grupos classificando as amostras como boas (3), regulares (2) ou ruins (1) quanto às características tintoriais e nitidez de visualização microscópica.

A proporção de células espermatogênicas visualizadas nos esfregaços foi comparada entre os dois tipos de coloração através de modelo linear geral (GLM) utilizando-se o software SAS ${ }^{\circledR}$ (SAS Institute, Cary, USA). Para avaliação da qualidade tintorial foi utilizado teste de regressão linear simples (Bioestat ${ }^{\circledR}$ 3.0, Belém do Pará, Brasil), onde a qualidade da coloração/visualização celular foi considerada como variável dependente (Escala de 1 a 3, onde 3=boa, $2=$ regular, $1=$ ruim) e o corante (Panótico ou Giemsa) como variável preditora.

\section{Resultados}

Todos os tipos celulares que compõe a linhagem germinativa testicular foram observados nas lâminas citológicas, independente da coloração utilizada para o processamento das amostras (Figuras 1 e 2).

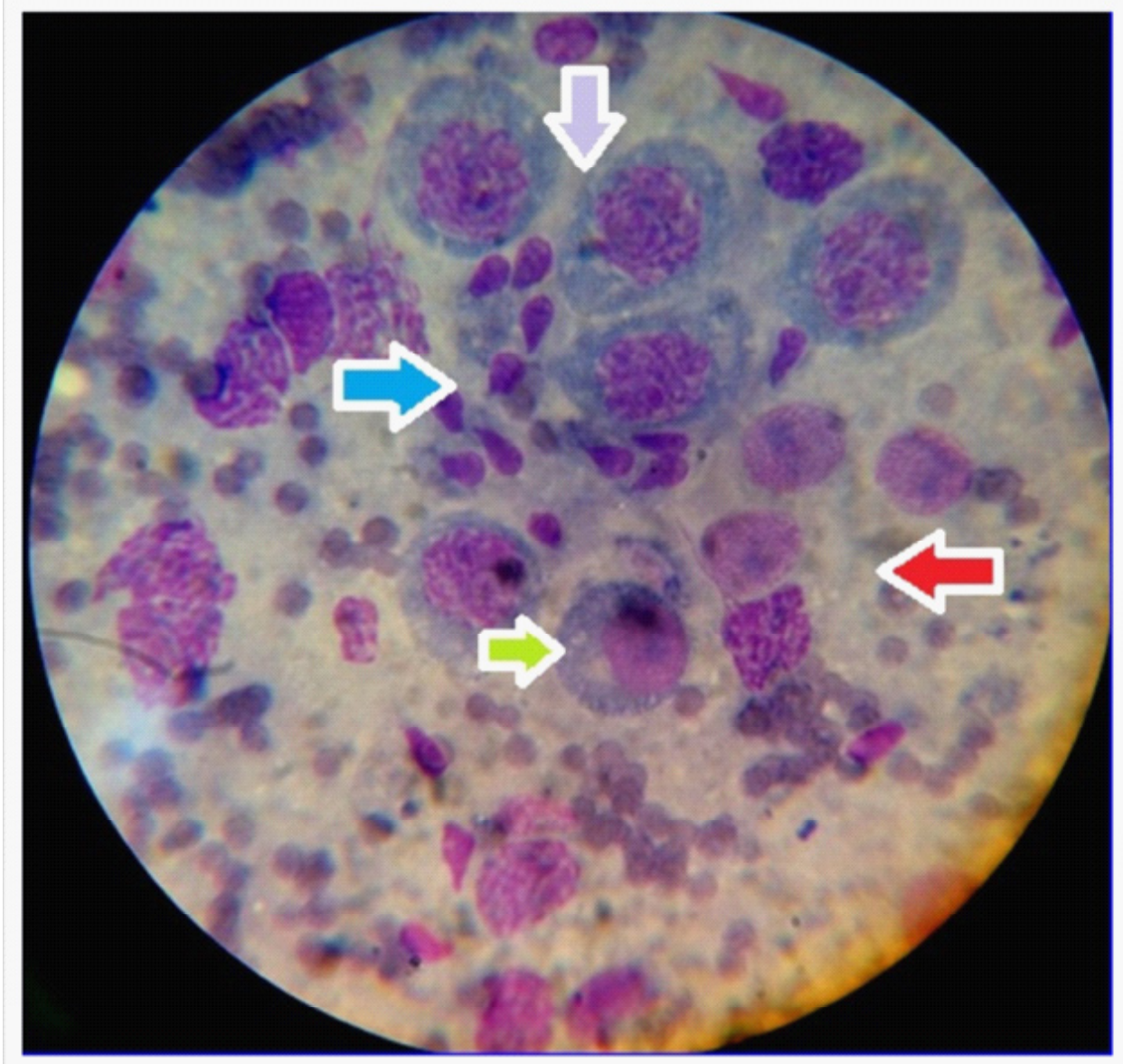

Figura 1. Citologia testicular corada com Giemsa e observação em microscopia de luz (aumento de 1000x). Na imagem podem ser identificadas células de Sertoli (seta vermelha; formato oval ou redondo,geralmente não apresentam citoplasma e possuem núcleo granular), espermatócitos primários (seta roxa; maior célula germinativa), espermátides finais (seta azul; núcleo alongado e bastante corado, geralmente vistos em grupos numerosos) e espermatogônia (seta verde; apresenta núcleo variando de oval a arredondado com o citoplasma escasso e basofílico). 


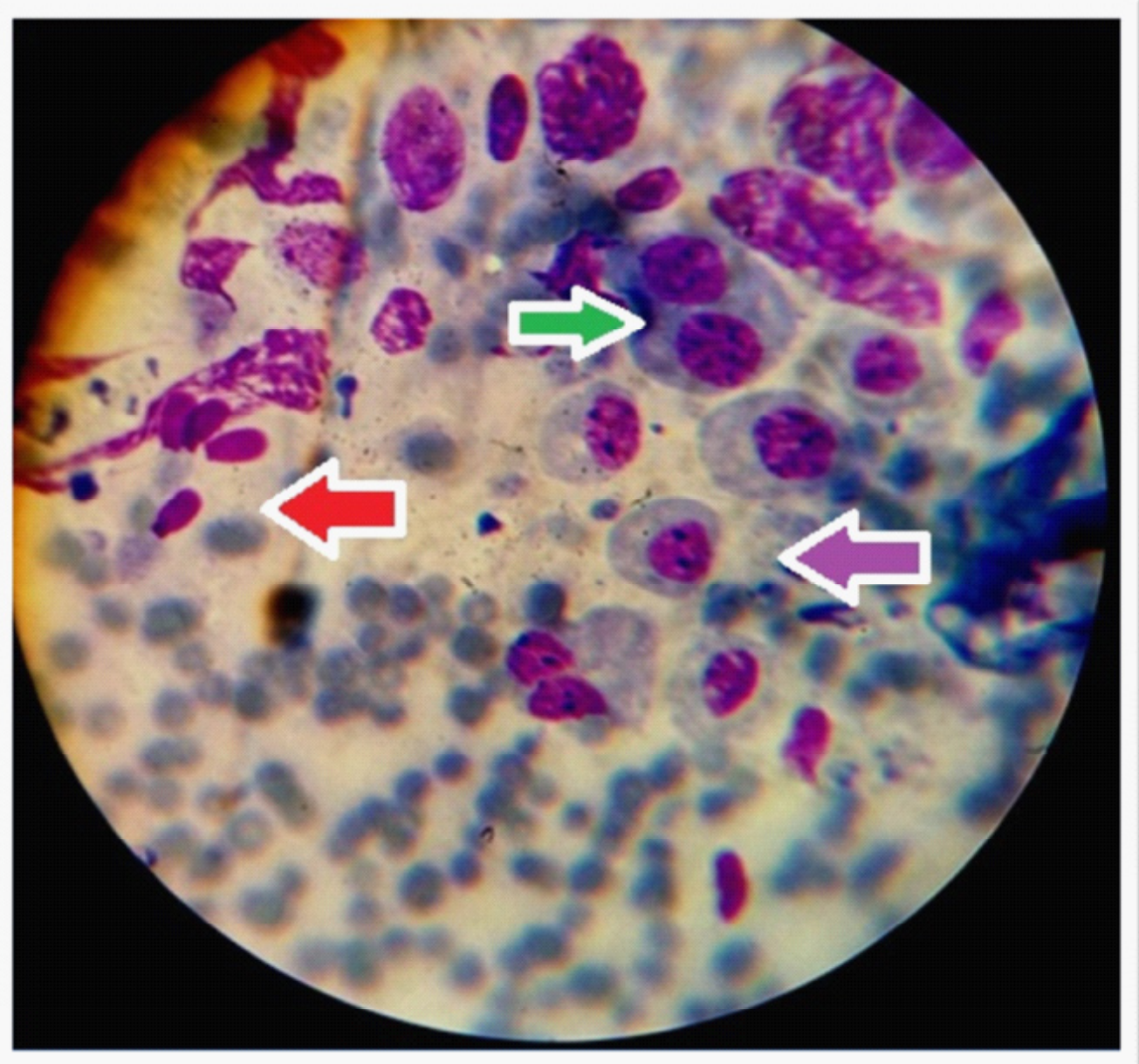

Figura 2. Citologia testicular corada com Panótico e observação em microscopia de luz (aumento de 1000x). Na imagem podem ser identificadas espermátides iniciais (seta roxa; conforme vão amadurecendo podem ser vistas em formato triangular, núcleo arredondado e em localização periférica), células em meiose (seta verde) e espermátides finais (seta vermelha).

As células de Sertoli e as espermátides finais representaram os tipos celulares mais prevalentes nos testículos submetidos às punções biópsias aspirativas ( $31,15 \%$ e $66,14 \%$, respectivamente), independente da técnica de coloração empregada. Já os espermatócitos secundários foram às células encontradas em menor proporção nos esfregaços pesquisados $(0,40 \%$ do total de células espermatogênicas).
Maior percentual $(\mathrm{p}<0,05)$ de espermatócitos secundários e células inflamatórias foram observadas nas lâminas citológicas coradas com Panótico em relação às coradas com Giemsa (Tabela-1). Não foram encontradas diferenças para a contagem dos demais tipos celulares em função do corante utilizado para o processamento dos esfregaços.

Tabela 1. Percentual (média \pm desvio) de células germinativas testiculares e células de Sertolli obtidas a partir de biópsia aspirativa testicular de bovinos adultos, de acordo com a técnica de coloração utilizada (Panótico Rápido ou Giemsa) para coloração dos esfregaços.

\begin{tabular}{cccc}
\hline Célula & Panótico Rápido & GIEMSA & p valor \\
\hline Espermatogônias & $1.07 \pm 3.50$ & $1.13 \pm 3.08$ & 0,8597 \\
\hline Espermatócitos primários & $0.27 \pm 1.30$ & $0.81 \pm 2.60$ & 0,8385 \\
Espermatócitos secundários & $0.58 \pm 1.85$ & $0.21 \pm 0.76$ & 0,0042 \\
\hline Espermátides iniciais & $5.34 \pm 13.03$ & $4.28 \pm 10.18$ & 0,2978 \\
Espermatídes finais & $59.02 \pm 25.58$ & $61.05 \pm 26.66$ & 0,8674 \\
\hline Espermatozoides & $0.44 \pm 2.58$ & $0.26 \pm 3.18$ & 0,1818 \\
Células de sertoli & $30.85 \pm 25.83$ & $30.42 \pm 25.60$ & 0,7765 \\
\hline Células inflamatórias & $0.83 \pm 2.92$ & $0.36 \pm 1.75$ & $\mathbf{0 , 0 3 1 8}$ \\
\hline
\end{tabular}


Houve efeito significativo da coloração sobre a qualidade de leitura dos esfregaços confeccionados a partir das PBAs testiculares $(\mathrm{p}=0,0087)$, sendo que maior proporção de lâminas classificadas como regulares $(38 \%)$ ou de boa qualidade (56\%) foram associadas à coloração com Panótico Rápido. Maior proporção de esfregaços com baixa qualidade ou falta de nitidez (32\%) foram atribuídos às lâminas citológicas coradas com Giemsa (Tabela-2).

Tabela 2. Avaliação da qualidade de leitura (Boa, Regular ou Ruim) das lâminas citológicas produzidas a partir de punções biópsias aspirativas testiculares de bovinos, de acordo com a técnica de coloração empregada (Panótico Rápido ou Giemsa).

\begin{tabular}{ccccc}
\hline & N & Boa & Regular & Ruim \\
\hline Panótico Rápido & 50 & $28(56 \%)$ & $19(38 \%)$ & $3(6 \%)$ \\
Giemsa & 50 & $21(42 \%)$ & $13(26 \%)$ & $16(32 \%)$ \\
\hline
\end{tabular}

\section{Discussão}

A punção biópsia aspirativa testicular tem se tornado uma importante técnica não apenas para o diagnóstico de patologias testiculares como também para a orientação do tratamento de pacientes humanos, ${ }^{12}$ equinos ${ }^{11}$ e bovinos. ${ }^{3}$ No entanto, de acordo com Leme e Papa $^{6}$ existe pouca informação disponível a respeito do uso da técnica de PBA em Medicina Veterinária, não havendo padronização dos métodos de colheita $\mathrm{e}$ processamento do material citológico.

Em nosso estudo a coloração Panótico Rápido foi a que proporcionou melhor visualização das células de linhagem espermatogênica, garantindo maior eficiência para a contagem diferenciação das estruturas testiculares. Nos trabalhos conduzidos por Paz et al., ${ }^{13}$ Araújo e Araújo ${ }^{14}$ e Souza et al., ${ }^{15}$ a técnica de coloração por Panótico mostrou-se eficiente para avaliação de esfregaços obtidos por PBA dos testículos de onças pintadas, pôneis e cachorros-do-mato, respectivamente, demonstrando a eficiência desse corante hematológico para o processamento dos aspirados testiculares.

A coloração Panótico também proporcionou maior nitidez para avaliação das células germinativas testiculares. Das 50 lâminas citológicas coradas com Panótico 47 (96\%) apresentaram qualidade de leitura boa ou regular, sendo que apenas 34 (68\%) lâminas coradas com Giemsa receberam a mesma classificação $(p<0,05)$. Resultados semelhantes foram obtidos por Costa et al., ${ }^{16}$ que observaram melhor qualidade e nitidez de coloração com Panótico Rápido em relação ao Giemsa para contagem do número de blastocistos de embriões murinos. De acordo com o mesmo estudo o corante Panótico confere maior agilidade na confecção das laminas, melhor nitidez de visualização das células embrionárias e menor tempo de exposição ao corante. A técnica de Panótico foi anteriormente utilizada para coloração de células de linhagem espermatogênica de touros ${ }^{17}$ ovinos ${ }^{18} \mathrm{e}$ felinos ${ }^{19}$ determinando boa qualidade de visualização, resultados semelhantes aos obtidos em nosso trabalho e que confirmam e validam o uso desse corante para o processamento de esfregaços obtidos por PBA testicular.

Em nosso trabalho foi observada maior proporção de espermátides iniciais e finais entre as células espermatogênicas mais prevalentes, resultados semelhantes aos reportados por Leme e Papa, ${ }^{6}$ que trabalharam com PBA em testículos equinos. De acordo com esses autores, as espermátides são células frequentes nos esfregaços testiculares e podem ser observadas durante as diferentes fases da espermiogênese. De acordo com Garolla et al., ${ }^{20} \mathrm{o}$ número de espermátides testiculares representa um marcador da normalidade da espermatogênese, sendo considerado como um importante indicador da saúde testicular. Dessa forma, pode-se concluir que os animais utilizados em nosso experimento apresentavam padrão normal de produção espermática durante a realização das PBAs.

$\mathrm{O}$ segundo tipo celular mais prevalente nos esfregaços testiculares foram às células de Sertoli. De acordo com Xu et al., ${ }^{21}$ as células de Sertoli são responsáveis pela base estrutural do epitélio seminífero, provendo suporte nutricional e hormonal para as células germinativas. Dessa forma, altas proporções de células de Sertoli também representam um marcador para normospermia, situação em que provavelmente se encontravam todos os animais incluídos em nosso estudo.

As células encontradas em menor quantidade em nossos esfregaços foram os espermatócitos secundários, resultado semelhante aos reportados por Leme, ${ }^{22}$; Leme, Papa e Roser, ${ }^{23}$; e Kanzawa et al., ${ }^{17}$ que trabalharam com esfregaços testiculares de cordeiros, equinos, e touros, respectivamente. De acordo com a bibliografia consultada, a menor frequência de espermatócitos secundários se justifica pela curta fase de tempo em que essas estruturas ocorrem nos testículos, que abrange exclusivamente o período da segunda divisão meiótica.

\section{Conclusão}

Ambas as colorações permitiram a identificação 
e visualização das células de linhagem espermatogênica, porém o Panótico Rápido garantiu a melhor qualidade de visualização das diferentes células germinativas testiculares. Dessa forma, conclui-se que o Panótico Rápido é a melhor opção para o preparo tintorial dos esfregaços obtidos através de PBA testicular em bovinos.

\section{Referências}

1 Pimentel, CA. Avaliação da fertilidade masculina em bovinos, In: I Simpósio de Reprodução Animal, 2008; Pelotas. Pelotas: Embrapa Clima Temperado, 2008. P. 7-22

2 Gandolfo, EF. Avaliação Reprodutiva em Touro [monografia]. São José do Rio Preto: Universidade Castelo Branco, Faculdade de Medicina Veterinária; 2007. 67p.

3 Chapwanya A, Callanan J, Larkin H, Keenan L, Vaughan L. Breeding soundness evaluation of bulls by semen analysis, testicular fine needle aspiration cytology and trans-scrotal ultrassonography. Irish Veterinary Journal. 2008; (61): 315-318

4 Rajwnshi A, Indudhara R, Goswami AK, Radhika S, Das A, Sharma SK, Vaidyanathan S, Datta BN. Fineneedle aspiration cytology in azoospermic males. Diagnostic Cytopathology. 1991; (7): 3-6

5 Carneiro RA, Horta RS. Exame citológico das neoplasias. Cadernos Técnicos de Veterinária e Zootecnia. 2013; (70): 27-35

6 Leme DP, Papa, FO. How to perform and interpret testicular fine needle aspiration in stallions. Journal of Equine Veterinary Science. 2010; (30): 590-596.

7 Teixeira LV, Lopes STA, Martins DB, França RT, Fighera RA. Punção aspirativa por agulha fina como método de coleta de material para a histopatologia no osteossarcoma canino. Pesquisa Veterinária Brasileira. 2010; (30): 145-148

8 Magalhães AM, Ramadinha RR, Barros CSL, Peixoto PV. Estudo comparativo entre citologia e histopatologia no diagnóstico de neoplasias caninas. Pesquisa Veterinária Brasileira. 2001; (21): 23-32

9 Raskin RE, Meyer DJ. Atlas de Citologia de Cães e Gatos. São Paulo: Roca; 2003.354p

10 Olicheski AT. Comparação entre os métodos de coloração panótico rápido e giemsa para diagnostico de protozoário Babesia (Starcovici, 1893) e de riquétsias do gênero Ehrlichia (Ehrlich, 1888) em cães (Canis familiaris) no município de porto alegre, RS, Brasil [Tese]. Porto Alegre: Universidade Federal do Rio Grande do Sul, Faculdade de Veterinária; 2003. 87p.

11 Papa FO, Leme DP. Testicular fine needle aspiration cytology from a stallion with testicular degeneration after external genitália trauma. Journal of Equine Veterinary Science. 2002; (22):121-124

12 Carpi A, Fabris FGM, Palego P, Coscio GDI, Romani R, Nardini V, Rossi $\mathrm{G}$. Fine-needle and large-needle percutaneous aspiration biopsy of testicles in men with nonobstructive azoospermia: safety and diagnostic performance. Fertility and Sterility. 2005; (83): 1029-1033

13 Paz RCR, Leme DM, Zuge RM, Pessuti C, Santos EF, Barnabe RC. Citologia por agulha fina (CAAF), em testículo de onça pintada (Pantheraonca), utilizada como ferramenta no diagnóstico de infertilidade. Brazilian Journal of Veterinary Research na Animal Science. 2003; (40): 100-107

14 Araújo AMS, Araújo SAC. Patologias mais comuns em garanhões da raça Pônei Brasileira. Archivos de Zootecnia. 2011; (60): 145-148.

15 Souza NP, Guimarães LD’A, Paz RCR. Dosagem hormonal e avaliação testicular em cachorro-do-mato (Cerdocyunthous) utilizando diferentes protocolos anestésicos. Arquivo Brasileiro de Medicina Veterinária e Zootecnia. 2011; (63): 1224-1228.
16 Costa EP, Lopes FG, Pereira ECM, Queiroz VLA, Macedo GG, Almeida Neto JRM, Costa AHA. Nova técnica para contagem do número de células de blastocistos. Arquivo Brasileiro de Medicina Veterinária e Zootecnia. 2010; (62): 1507-1510

17 Kanazawa MY, Scott C, Wilges CHM, Dias LGGG, Souza FF. Correlação da circunferência escrotal, citologia testicular e parâmetros do sêmen de epidídimos de touro. Enciclopédia Biosfera. 201(8):517-527.

18 Pardo FJD, Assis ER, Miyazawa MK, Borge LH. Avaliação da espermatogênese pela citologia aspirativa por agulhafina (CAAF) em testículos de cordeiros pré-púberes. Revista Científica Eletrônica de Medicina Veterinária. 2005; (4).

19 Leite DKVH. Avaliações das características histológicas, citológicas, clínicas e seminais de felinos domésticos (Feliuscatus, LINNAEUS, 1758) e selvagens (Leopardustigrinus, SCHREBER, 1775), Leopardusgeoffroyi, d'ORBIGN \& GERVAIS, 1843 e Puma yagouaroundi, E. GEOFFROYI, 1803), FELIDAE CARNIVORA [Tese]. Niterói: Universidade Federal Fluminense, Faculdade de Veterinária; 2009.146p.

20 Garolla A, Selice R, Engl B, Bertoldo A, Menegazzo M, Finos L, Lenzi A, Foresta C. Spermatid count as a predictor of response to FSH therapy. Reproductive Biomedicine Online. 2014; (29): 102-112.

21 Xu B, Chen M, Ji X, Yao M, Mao Z, Zhou K, Xia Y, Han X, Tang W. Metabolomic profiles reveal key metabolic changes in heat stress-treated mouse Sertoli cells. Toxicology in Vitro. 2015; (29): 1745-1752.

22 Leme DP. Citologia do epitélio seminífero de carneiros. Revista Científica Eletrônica de Medicina Veterinária. 2004; (4).

23 Leme DP, Papa FO, Roser JF. Reproductive characteristics of stallions during the breeding and non-breeding season in a tropical region. Tropical Animal Health and Production. 2012; (44): 1703-1707. 